Diabetologia 7, 308-315 (1971)

C by Springer-Verlag 1971

\title{
Platelet Adhesiveness and Aggregation in Relation to Diabetic Retinopathy
}

\author{
H. Heath, W.D. Brigden, J.V. Canever, J. Pollook, P.R. Honter, J. Kelsey and A. Bloom \\ Department of Biochemical Pathology, University College Hospital Medical School, London, England
}

Received: March 25, 1971, accepted: July 15, 1971

Summary. Platelet adhesiveness, ADP-activated platelet aggregation and the activity of the ADP-splitting enzymes in blood and plasma have been studied in 22 diabetics with severe retinopathy, 22 long-duration diabetics with minimal or no retinopathy and 28 control subjects. The rate of platelet aggregation under the in. fluence of $5,3,2$ and $1 \mu \mathrm{M}$ ADP, the maximum aggrega. tion attained and the rate of disaggregation of these aggregates were measured. The platelets from actively deteriorating retinopaths were found to be more sensitive to the effect of low concentrations of ADP; a significant increase in the extent of aggregation and a decrease in the rate of disaggregation of platelet aggregates formed under the experimental conditions, in vitro were observed. If this should oceur in vivo, then capillary occlusion might ensue. This increased sensitivity to ADP and inability to disaggregate, was not due to any differences in the activity of the ADP-splitting enzyme systems in blood. Significant differences in the parameters were not observed when the large diabetic groups were compared with the control subjects. Contrary to some reports, an increase in platelet adhesiveness was not apparent in either diabetic group.

Adhesivité et agregation des thrombocytes en relation aveo la rétimopathie diabétique.

Résumé. L'adhésivité des thrombocytos, l'activation par l'ADP de leur agrégation et l'activité des enzymes scindant l'ADP dans le sang et le plasma ont été étudiés chez 22 diabétiques porteurs de rétinopathie grave, chez 22 sujets diabétiques anciens avec une rétinopathie minime ou nulle et chez 28 sujets témoins. On a mesuré le taux d'agrégation des thrombocytes sous l'effet de $\mathbf{5}$, 3,2 et $1 \mu \mathrm{M}$ d'ADP, le maximum d'agrégation atteint et le taux de désagrégation de ces agrégats. Les thrombocytes des sujets atteints de rétinopathie fortement évolutive sont apparus plus sensibles à l'effet de faibles concentra. tions d'ADP; on a observé un accroissement significatif du degré d'agrégation é une diminution de la vitesse de désagrégation des agrégats thrombocytaires formés dans les conditions expérimentales in vitro. Si cela se produisait in vivo, il pourrait en résulter une occlusion des capillaires. Cette sensibilité accrue à l'ADP et cette incapacité à se désagréger n'étaient pas dues à une différence dans l'acti- vité du système d'enzymes scindant l'ADP dans le sang. On n'observe pas de différences significatives dans ces paramètres si l'on compare le groupe important des dia. bétiques avec les sujets témoins. Contrairement à certains rapports, aucun des deux groupes de diabétiques ne présentait d'accroissement apparent de l'adhésivité des thrombocytes.

Thrombocyten-Adhäsion und-Aggregation und ihre Beziehungen zur diabetischen Retinopathie

Zusammenfassung. An 22 Diabetikem mit schwerer Retinopathie, an weiteren 22 Diabetikern mit langem Krankheitsverlauf, aber keiner oder minimaler Retinopathie und an 28 Kontrollpersonen wurde die Adhäsion der Thrombocyten, die Aggregation der durch ADP aktivierten Thrombocyten und die Aktivität von ADP spaltenden Encymen im Blut und Plasma gemessen. Der Grad der Thrombocytenaggregation, ihr Maximum und der Grad der Desaggregation wurden unter dem Einfluß von $5,3,2$, und $1 \mu$ M ADP bestimmt. Die 'Thrombocyten bei aktiv fortschreitender Retinopathien waren gegenüber der Wirkung von geringen Konzentrationen von ADP empfindlicher. Es wurde auch eine signifikante Erhöhung des Ausmaßes der Aggregation und eine Ver. minderung des Desaggregationsgrades von Thromboeytenaggregaten, die sich unter in vitro Bedingungen gebildet hatten, festgestellt. Wenn dies in vivo vorkommen sollte, kann daraus ein Verschluß von Kapillaren entstehen. Die erhöhte Empfindlichkeit gegenüber ADP und die Unfähigkeit zur Desaggregation war nicht auf Unterschiede in der Alktivität von. ADP spaltenden Enzymen des Blutsystems zurückzuführen. Bei dem Vergleich der großen Gruppe von Diabetikern mit der Kontrollgruppe wurden keine signifikanten Unterschiede der Parameter aufgedeckt. Im Gegensatz zu einigen Berichten in der Literatur konnte bei keiner der Diabetikergruppen eine Erhöhung der Adhäsion von Thromboeyten gefunden werden.

Key-words: Diabetes, retinopathy, platelet adhesiveness, ADP activated platelet aggregation, ADP splitting enzymes.
The susceptibility of patients with diabetes to cardiovascular complications, has led several investigators to study abnormalities in platelet adhesiveness in diabeties. It has been shown [10] that there is an increase in platelet adhesiveness in diabetics when considered as a group, and that this is especially marked in those who also have ischaemic heart disease. However, there are considerable variations in this parameter, and individual values for both control and diabetic subjects. vary so much that it is not possible to distinguish between these on an individual basis.
These findings are in general agreement with those of other investigators of platelet adhesiveness $[5,6,14$, $15]$.

Although the prevalence of diabetic retinopathy is usually related to the duration of the disease, the rate at which this complication develops in different patients can vary markedly. It was therefore decided to study two groups of diabetics who could be considered to be either prone or resistant to the development of this complication. The latter were those patients who had had diabetes for at least 17 years 
and yet showed ophthalmoscopically either minimal or no signs of retinopathy. The other group consisted of patients with severe retinopathy.

One of the earliest observable pathological changes in the retina of diabetics is that small areas of the capillary bed are non-perfusable with fluorescein [9]. Whether this loss of patency is brought about by narrowing of the lumen due to endothelial proliferation or basement membrane thickening, or by occlusion with erythrocyte or platelet aggregates, is not known. Because of the reported increase in platelet adhesiveness in diabeties, it was thought desirable to investigate platelet behaviour more fully, in order to determine whether there was any relationship between ADP activated aggregation and platelet adhesiveness, and the development of diabetic retinopathy.

\section{Clinical Material}

Group $A$; This consisted of 22 patients, 13 males and 9 females of average age 52 years (range 32 to 77 years) and a mean duration of diabetes of 24 years (range 17 to 48 years). Fifteen were on insulin and four on oral treatment. These patients were selected by careful ophthalmoscopic examination from those attending the Out-Patient clinies [8]. None had more than a total of five microaneurysms in both eyes, even though the duration of the diabetes was at least 17 years. Apart from these few microaneurysms, detected after prolonged and repeated examinations, the fundi were apparently normal.

Group $A+:$ This consisted of 6 patients, 3 males and 3 females, of average age 51 years (range 41 to 68 years) and a mean duration of diabetes of 23 years (range 17 to 30 years). Four were on insulin and two on oral treatment. These patients were selected from Group A on the criteria that the retinae were completely devoid of microaneurysms and the fundi were apparently quite normal.

Group B: This consisted of 22 patients, 13 males and 9 females, of average age 52 years (range 27 to 74 years) and a mean duration of diabetes of 19 years (range 1 to 35 years). Nineteen were on insulin and three on oral treatment. These were selected by ophthalmological and photographic methods from those patients with severe retinopathy attending the Out-Patient clinics, on the basis of one or more of the following criteria: (a) a combined retinal score for both eyes on the Hammersmith Scale [11] of more than 9 for microaneurysms, (b) six or more blob haemorrhages or (c) a pre-retinal haemorrhage during or six months before the study.

Group $B+$ : This consisted of 6 patients, 4 males and 2 females, of average age 53 years (range 27 to 74 years) and a mean duration of diabetes of 17 years (range 1 to 26 years). All were on insulin. These patients were selected from Group B on the basis that any of the above criteria had deteriorated during the course of the study.
Controls: These consisted of 28 non-diabetic volunteers from the Medical School staff, 17 males and 11 females, of average age 50 years (range 31 to 69 years).

\section{Methods}

Blood Specimen: $27 \mathrm{ml}$ of blood was withdrawn from the antecubital vein by clean venepuncture without venestasis, through a No. $19 \mathrm{G}$ needle into a $35 \mathrm{ml}$ plastic syringe containing $3 \mathrm{ml}$ of $3.8 \% \mathrm{w} / \mathrm{v}$ sodium citrate.

Platelet-rich plasma (PRP): This was prepared by centrifuging the citrated blood in siliconized tubes at $170 \times g$ for $15 \mathrm{~min}$. The supernatant PRP was transferred using a polythene Pasteur pipette, to a plastic container. The platelet count was determined by the method of Brecher and Cronkite [4] using phasecontrast microscopy on a $1: 200$ dilution of this PRP with platelet diluting fluid (Clintech Ltd.). A suitable portion of this PRP was centrifuged in a siliconized tube at $1200 \times g$ for $15 \mathrm{~min}$, and the supernatant plateletpoor plasma (PPP) was decanted and used to dilute the PRP, so that it contained 300000 platelets per $\mathrm{mm}^{3}$.

Platelet aggregation: This was determined by a modification of the method of Born [2] using an EEL Aggregation Meter in conjunction with a Bryans Recorder (Model : 27000). $1.0 \mathrm{ml}$ of the standardized PRP was transferred to a plastic EEL aggregation tube with a $1 \mathrm{ml}$ plastic hypodermic syringe and incubated at $37^{\circ}$ for $5 \mathrm{~min}$. The tube was then placed in the aggregation meter, stirred at a constant speed and the instrument was adjusted to give a standard voltage out-put. The voltage out-put given by $1 \mathrm{ml}$ of PPP under the same conditions was then recorded. The PRP tube was replaced in the machine and the voltage out-put checked. $0.1 \mathrm{ml}$ of an adenosine diphosphate (ADP) solution was then added to give a final concentration of either 5, 3, 2 or $1 \mu \mathrm{M}$. The stirrer and recorder were switched on immediately and the changes in voltage out-put were recorded for at least $3 \mathrm{~min}$ using a chart speed of $3 \mathrm{~cm} / \mathrm{min}$. The rate of stirring, the concentration of platelets in the PRP and the initial voltage out-put for the PRP were kept constant for each determination.

Platelet Adhesiveness: This was determined exactly $30 \mathrm{~min}$ after blood withdrawal, by a modification of the method of Hellem [7]. $2 \mathrm{ml}$ of the citrated blood was placed in a mechanically driven plastic syringe and passed through a $2.5 \mathrm{~g}$ column of glass ballotini $(0.45-0.52 \mathrm{~mm}$ diameter) retained in a $5 \mathrm{~mm}$ bore PVC tube by fine washed silk mesh. The syringe was set to deliver $2 \mathrm{ml}$ in $30 \mathrm{sec}$ and the leading edge of the blood traversed the column in 17 sec. The glass ballotini were washed with a $5 \%$ solution of sodium bicarbonate, then copiously with redistilled water and dried at $110^{\circ}$ before use. Platelet counts were determined on the blood before and after passage through the column, and 
the platelet adhesiveness is expressed as the percentage of platelets retained.

The activity of ADP-splitting enzyme systems in whole blood and plasma: $1 \mathrm{ml}$ ADP solution $(0.2 \mathrm{mg} / \mathrm{ml})$ was added to $1 \mathrm{ml}$ blood and the mixture incubated at $37^{\circ}$ for $20 \mathrm{~min}$. After cooling and centrifuging at $8000 \times g$ for $10 \mathrm{~min}, 1 \mathrm{ml}$ of the supernatant was mixed with $2 \mathrm{ml}$ of $3.5 \%$ perchloric acid. The solution was allowed to stand at $4^{\circ}$ for $15 \mathrm{~min}$, centrifuged at $1200 \times g$ for $15 \mathrm{~min}$ and $2 \mathrm{ml}$ of the supernatant was used for the determination of ADP using a Biochemica Test Combination (Boehringer, Catalogue No: TC-K 15980).

$0.5 \mathrm{ml}$ ADP solution $(0.2 \mathrm{mg} / \mathrm{ml})$ was added to $0.5 \mathrm{ml}$ plasma and the mixture incubated at $37^{\circ}$ for $1 \mathrm{~h}$. After cooling, $2 \mathrm{ml}$ of $3.5 \%$ perchloric acid solution was added and the resulting suspension treated as for whole blood.

Blank values were determined by omitting the incubation period after the addition of $A D P$, and the activity of the ADP-splitting enzyme systems is taken as the difference between the values for ADP obtained with and without incubation.

\section{Results}

Platelet Aggregation: When ADP is added to a suspension of platelets in plasma, the optical properties of the suspension alter, due to a complex and sometimes superimposed sequence of changes. The platelets, after altering shape and causing a slight increase in optical density, rapidly form small aggregates of up to 10 units. These small aggregates, in which individual platelets are still discernible, further aggregate to form larger loosely packed clumps. In the presence of high concentrations of ADP, such as $5 \mu \mathrm{M}$, these clumps contract to become more dease; further ADP is released from these platelets and aggregation continues rapidly to reach a maximum irreversible level. In the presence of lower concentrations of ADP, this final stage is not always reached and some disaggregation of the loosely packed clumps occurs [3]. The effect of $5,3,2$ and $1 \mu \mathrm{M}$ ADP on a $300000 / \mathrm{mm}^{3}$ platelet suspension from a normal subject, is shown in Fig 1.

In assessing therefore, the susceptibility of platelets from normal and diabetic subjects to the aggregating action of $\mathrm{ADP}$, it is desirable to be able to derive parameters for the extent of aggregation at any given time and for the rates of aggregation and disaggregation. The interpretation of the changes in the optical properties of the suspension is made difficult because of the limitations in the experimental procedure, necessitated by the fact that the properties of the platelets would alter if these were separated from the plasma and suspended in a medium of known optical density. In order to overcome this problem, the aggregation meter was set so that all specimens of platelet-rich plasma gave a fixed voltage out-put $(\mathrm{Vr})$ to the pen recorder. The voltage out-put (Vp) from the corresponding platelet-poor plasma was then measured.
The difference between these two voltage outputs $(V \mathrm{p}-\mathrm{Vr})$ varied between specimens according to the optical density of the platelet-poor plasma. The contribution to the optical density' of the platelet-rich plasma by the platelets was constant, since each suspension was diluted with platelet-poor plasma to contain 300000 platelets per $\mathrm{mm}^{3}$.

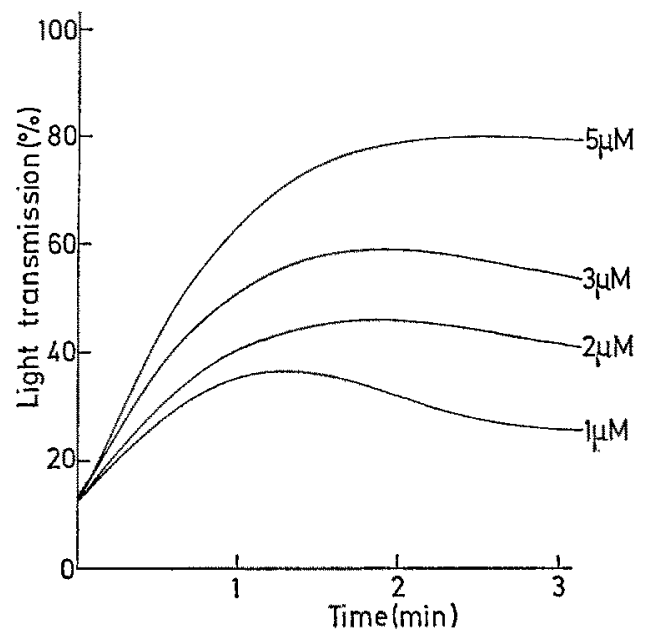

Fig. 1. Recordings of changes in light transmission due to the aggregation of platelets from normal human subjects in the presence of $5,3,2$ and $1 \mu \mathrm{M}$ ADP

If $\mathrm{Vm}$ is the voltage out-put from the maximally aggregated suspension, then the extent of aggregation (Ta) is represented by the expression $\frac{V_{m}-V \mathbf{r}}{V p-V r} \times 100$. This in fact is the percentage change in transmission between platelet-poor and platelet-rich plasma. This can also be represented as a change in optical density, by use of the expression $\mathrm{Da}=2 \log \mathrm{Ta}$, where $\mathrm{Da}=$ the optical density of the maximally aggregated suspension.

(A) The extent of aggregation: The extent of maximal aggregation caused by final concentrations of $5,3,2$ and $1 \mu \mathrm{M}$ ADP on the platelets from selected groups of diabetic and normal subjects, is shown in Table 1. From this it can be seen that the extent of aggregation in all groups decreases with decreasing concentrations of ADP. At the highest concentration of ADP, i.e. $5 \mu \mathrm{M}$, when disaggregation does not take place, there are no statistically significant differences between the mean values of Ta for any group. At lower concentrations of ADP in which disaggregation as well as aggregation is taking place, it can be seen that $\mathrm{Ta}$ for the B + Group of actively deteriorating retinopaths, is greater than the Ta for the A+ Group of longduration diabeties who had no detectable retinopathy, being $41 \pm 2.9$ and $29 \pm 2.7$ at $1 \mu \mathrm{M}$ ADP; $66 \pm 5.3$ and $41 \pm 1.8$ at $2 \mu \mathrm{M}$ ADP and $72 \pm 3.7$ and $58 \pm 3.7$ at $3 \mu \mathrm{M}$ ADP, respectively. These differences are all statistically significant $(p<0.01)$. There are no statistically significant differences, however, in the 
extent of platelet aggregation at these lower concentrations of ADP between the values for the normal subjects and either of the large groups of diabetic patients.

When the extent of aggregation is represented by the parameter $\mathrm{Da}$ (Table 2), the mean value at $1 \mu \mathrm{M}$ ADP for the A+ Group of 0.55 is $42 \%$ greater than the patients with deteriorating retinopathy. Thus, the platelets from the latter group had aggregated into larger, and as will be seen later, more stable masses. Similar results were obtained for higher concentrations of $\mathrm{ADP}$, the corresponding increases in relative optical density being 105,71 and $27 \%$ at 2,3 and $5 \mu \mathrm{M}$ ADP respectively.

Table 1. The extent of $A D P$-activated aggregation of platelets from selected groups of diabetic and nomal subjects

\begin{tabular}{|c|c|c|c|c|}
\hline \multirow[t]{2}{*}{ Subjects (No.) } & \multicolumn{4}{|c|}{ Extent of aggregation (Ta) at ADP concentrations of: } \\
\hline & $5 \mu \mathrm{M}$ & $3 \mu \mathrm{M}$ & $2 \mu \mathrm{M}$ & $1 \mu \mathrm{M}$ \\
\hline $\begin{array}{ll}\text { Normals } & (28) \\
\text { Group } A & (22)\end{array}$ & $72 \pm 3.2$ & $58 \pm 3.5$ & $49 \pm 3.5$ & $32 \pm 2.0$ \\
\hline $\begin{array}{l}\text { Minimal } \\
\text { Retinopathy } \\
\text { Group } B \\
\text { (22) }\end{array}$ & $75 \pm 1.8$ & $62 \pm 2.3$ & $46 \pm 2.4$ & $32 \pm 1.6$ \\
\hline $\begin{array}{l}\text { Severe } \\
\text { Retinopathy } \\
\text { Group } A+\quad(6)\end{array}$ & $71 \pm 3.3$ & $61 \pm 3.5$ & $51 \pm 3.8$ & $33 \pm 1.9$ \\
\hline No & $75 \pm 3.3$ & $58 \pm 3.7$ & $41 \pm 1.8$ & $29 \pm 2.7$ \\
\hline $\begin{array}{l}\text { Group } B+\quad(6) \\
\text { Deteriorating } \\
\text { Retinopathy }\end{array}$ & $78 \pm 4.0$ & $72 \pm 3.7$ & $66 \pm 5.3$ & $41 \pm 2.9$ \\
\hline
\end{tabular}

a Expressed as the percentage of the light transmitted through the suspension of aggregated platelets, when PRP and PPP are taken as $0 \%$ and $100 \%$ respectively.

Table 2. Values for the mean relatwe optical densities of platelet-rich plasma after ADP-activated aggregation from selected groups of normal and diabetic subjects

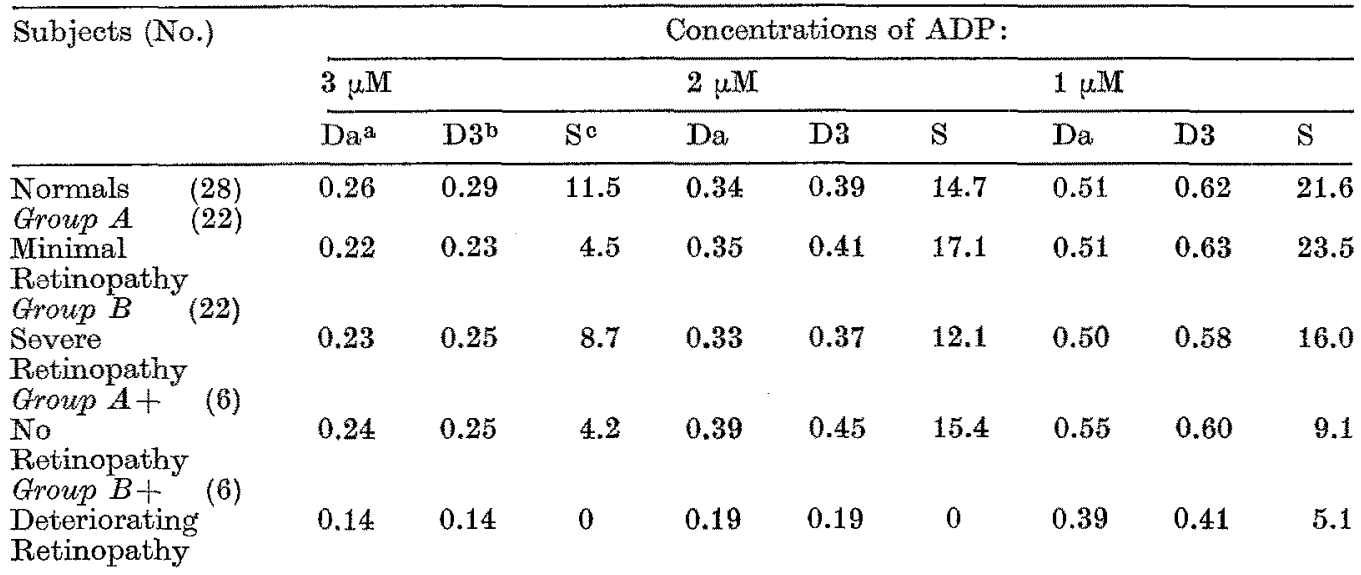

a $\mathrm{Da}=$ Relative optical density of maximally aggregated platelet suspension.

b D3 = Relative optical density of platelet suspension 3 min after addition of ADP.

c $\mathrm{S}=$ Percentage increase in relative optical density due to disaggregation.

mean value for the $B+$ Group of 0.39 . This can be taken as a measure of the extent to which disaggre. gation has taken place in the diabetic group without retinopathy, compared with the deteriorating retinopaths, since the $42 \%$ increase in relative optical densities means that the maximally aggregated suspension of platelets from Group $\mathrm{A}+$, contained the optical equivalent of $42 \%$ more light-absorbing aggregates than the comparable suspension from those
(B) The rate of aggregation: The parameter chosen to give an indication of the net overall rate of aggregation is the maximum gradient (Ga) of the voltage change recording during aggregation. This is expressed. as the percentage change per second between $\mathrm{Vr}$ and $V p$, and can be determined more accurately than the time for maximum aggregation, since at high concentrations of ADP this is not sharply defined. As can be seen from Table 3 , the net overall rate of aggregation 
is generally dependent upon the concentration of ADP, with values for $\mathrm{Ga}$ being greatest with $5 \mu \mathrm{M}$ $A D P$, for the control and both groups of diabetic subjects. The one exception is in the case of the severely deteriorating retinopaths where $\mathrm{Ga}$ is greatest at a final concentration of $3 \mu \mathrm{M}$ ADP. Although at lower concentrations of ADP there was a significant increase in the extent of aggregation attained by the deteriorating retinopaths, there were no significant differences in the rate at which this took place, the values of $\mathrm{Ga}$ at $1 \mu \mathrm{M}$ being $0.73 \pm 0.07$ and $0.66 \pm 0.05$ for those with deteriorating retinopathy and those without retinopathy, respectively. There were no significant differences between values of $\mathrm{Ga}$ for the Control group and either of the diabetic groups at any concentration of ADP.

(C) The stability of the aggregates: As can be seen from Fig. 1, the platelet aggregates formed in the presence of $5 \mu \mathrm{M} A D P$ do not disaggregate again, but difference between the values of Gd for the larger groups of diabetics with and without retinopathy of $0.11 \pm 0.01$ and $0.19 \pm 0.02$ is statistically significant $(p<0.01)$. The difference between the values of $\mathrm{Gd}$ of $0.03 \pm 0.02$ and $0.19 \pm 0.03$ for the rate of disaggregation of the platelet aggregates formed in the presence of $1 \mu \mathrm{M}$ ADP by the actively deteriorating retinopaths and those without retinopathy, is also statistically significant $(p<0.002)$. It should be noted that disaggregation does not occur in the case of the actively deteriorating retinopaths when concentrations of 2 and $3 \mu \mathrm{M}$ ADP are used, the values for Gd being zero in both cases. The inability of these platelet aggregates to disaggregate again is shown in Fig 2, which demonstrates the mean behaviour of the platelets from Groups A+, B+ and normal subjects in the presence of $2 \mu \mathrm{M}$ ADP. It should be noted that the extent of aggregation attained by the Group B+ subjects in the presence of $2 \mu \mathrm{M}$ ADP is far greater

Table 3. The maximum rate of ADP-activated aggregation of platelets from selected groups of diabetic and normal subjects

\begin{tabular}{|c|c|c|c|c|}
\hline \multirow[t]{2}{*}{ Subjects (No.) } & \multicolumn{4}{|c|}{ Maximum rate of aggregation $(\mathrm{Ga})^{\mathrm{a}}$ at $\mathrm{ADP}$ concentrations of: } \\
\hline & $5 \mu \mathrm{M}$ & $3 \mu \mathrm{M}$ & $2 \mu \mathrm{M}$ & $1 \mu \mathrm{M}$ \\
\hline $\begin{array}{ll}\text { Normals } & (28) \\
\text { Group } A & (22)\end{array}$ & $0.91 \pm 0.03$ & $0.87 \pm 0.04$ & $0.80 \pm 0.04$ & $0.62 \pm 0.04$ \\
\hline $\begin{array}{l}\text { Minimal } \\
\text { Retinopathy } \\
\text { Group } B\end{array}$ & $0.99 \pm 0.04$ & $0.93 \pm 0.04$ & $0.80 \pm 0.04$ & $0.62 \pm 0.03$ \\
\hline $\begin{array}{l}\text { Severe } \\
\text { Retinopathy }\end{array}$ & $0.88 \pm 0.04$ & $0.88 \pm 0.04$ & $0.74 \pm 0.04$ & $0.63 \pm 0.03$ \\
\hline $\begin{array}{l}\text { Group } A+\quad(6) \\
\text { No } \\
\text { Retinopathy }\end{array}$ & $0.99 \pm 0.05$ & $0.87 \pm 0.05$ & $0.78 \pm 0.03$ & $0.66 \pm 0.05$ \\
\hline $\begin{array}{l}\text { Group } B+(6) \\
\text { Deteriorating } \\
\text { Retinopathy }\end{array}$ & $0.89 \pm 0.09$ & $0.94 \pm 0.07$ & $0.78 \pm 0.05$ & $0.73 \pm 0.07$ \\
\hline
\end{tabular}

a $\mathrm{Ga}=$ The maximum gradient (\%/sec) of the voltage change recording during aggregation.

with lower concentrations of ADP the aggregates are less stable. Two parameters have been chosen to give a measure of the stability of the platelet aggregates. The rate of disaggregation is indicated by the maximum gradient (Gd) of the voltage change recording, after maximum aggregation has taken place. This has a value of zero when disaggregation does not occur and since the stability of platelet aggregates is dependent upon the extent of the aggregation that has taken place, the stability (S) can also be represented as the percentage increase in relative optical densities occurring between maximum aggregation and a fixed time after the addition of the ADP. In most cases, stable conditions ensued 3 min after the addition of ADP and this time was arbitrarily selected.

The values of $\mathrm{Gd}$ for the rate of disaggregation after aggregation has been initiated by either 3, 2 or $1 \mu \mathrm{M}$ ADP, are given in Table 4. Contrary to the values for $\mathrm{Ga}$, these values increase with decreasing concentrations of ADP. At a concentration of $1 \mu \mathrm{M}$, the
Table 4. The maximum rate of disaggregation of $A D P$. induced platelet aggregates from selected groups of diabetic and normal subjects

\begin{tabular}{|c|c|c|c|}
\hline \multirow[t]{2}{*}{ Subjects (No.) } & \multicolumn{3}{|c|}{$\begin{array}{l}\text { Maximum rate of disaggregation }(\mathrm{Gd})^{\mathrm{a}} \\
\text { at ADP concentrations of: }\end{array}$} \\
\hline & $3 \mu \mathrm{M}$ & $2 \mu \mathrm{M}$ & $1 \mu \mathrm{M}$ \\
\hline $\begin{array}{ll}\text { Normals } & (28) \\
\text { Group A } & (22)\end{array}$ & $0.03 \pm 0.01$ & $0.06 \pm 0.01$ & $0.13 \pm 0.02$ \\
\hline $\begin{array}{l}\text { Minimal } \\
\text { Retinopathy } \\
\text { Group } B \\
\text { (22) }\end{array}$ & $0.02 \pm 0.01$ & $0.09 \pm 0.02$ & $0.19 \pm 0.02$ \\
\hline $\begin{array}{l}\text { Severe } \\
\text { Retinopathy }\end{array}$ & $0.02 \pm 0.01$ & $0.05 \pm 0.02$ & $0.11 \pm 0.01$ \\
\hline $\begin{array}{l}\text { Group } A+\quad(6) \\
\text { No } \\
\text { Retinopathy }\end{array}$ & $0.01 \pm 0.01$ & $0.11 \pm 0$ & $0.19 \pm 0.03$ \\
\hline $\begin{array}{l}\text { Group } B+(6) \\
\text { Deteriorating } \\
\text { Retinopathy }\end{array}$ & 0 & 0 & $0.03 \pm 0.02$ \\
\hline
\end{tabular}

a $\mathrm{Gd}=$ The maximum gradient $(\% / \mathrm{sec})$ of the voltage change recording during disaggregation. 
than that of either the normal subjects or the Group $\mathrm{A}+$ diabetics, and thus the Group B+ platelets can be seen to have an increased sensitivity to the action of ADP, whereas the Group A+ platelets have a decreased sensitivity when compared with the mean normal behaviour.

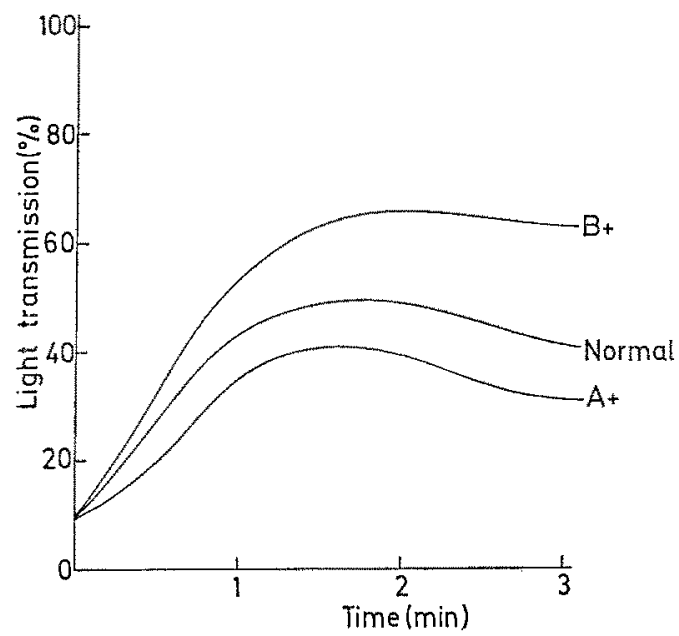

Fig. 2. Changes in light transmission due to the aggregation of platelets by $2 \mu \mathrm{M}$ ADP from diabetics with no retinopathy $(A+)$, with deteriorating retinopathy $(B+)$ and normal subjects

Fig. 3, the effect of $1 \mu \mathrm{M}$ ADP on the platelets from two diabetic patients is shown. The first patient (A.M.) was a 55 year old male, who had had diabetes for 30 years, was insulin dependent and yet had completely normal fundi. The other patient (R.B.) was a 74 year old male, who had had diabetes for 26 years, was insulin dependent and had severe retinopathy, the development of numerous microaneurysms and haem. orrhages having taken place in the months preceding this platelet study. It will be seen that the platelets from the actively deteriorating retinopath (R.B.) do not disaggregate at all, whereas disaggregation can be observed in the case of the non-retinopath (A.M.) after maximum aggregation has been attained. It will be noted that the extent of aggregation in the latter case is much less, probably because aggregation and disaggregation are occurring simultaneously and this is reflected in the slower rate of aggregation for this patient (A.M.).

Values for $\mathrm{S}$, the percentage increase in relative optical density due to disaggregation, are given in Table 2. From this it can be seen that the behaviour of the platelets from the control subjects and Group A diabetics are similar, the percentage increase in lightabsorbing particles due to disaggregation being 11.5 , 14.7 and 21.6 for the controls and 4.5, 17.1 and 23.5 for the Group A diabetics, at concentrations of 3,2 and $1 \mu \mathrm{M}$ ADP. In the case of the diabetics with actively deteriorating retinopathy, disaggregation did not take place when either 3 or $2 \mu \mathrm{M}$ ADP was used to initiate the aggregation, and only a $5.1 \%$ increase occurred with
$1 \mu \mathrm{M}$ ADP. This was due to the fact that the plateletrich plasma from these patients was more sensitive to the action of ADP, the extent of aggregation (Table 1) brought about by $1 \mu \mathrm{M}$ ADP, $(\mathrm{Ta}=41.0)$ was the same as that caused by $2 \mu \mathrm{M}$ ADP on the platelets from the Group A+ diabetics. The effect of $2 \mu \mathrm{M}$ ADP on the Group B + platelets was greater than the effect of $3 \mu \mathrm{M}$ ADP on the platelets from any of the other groups.

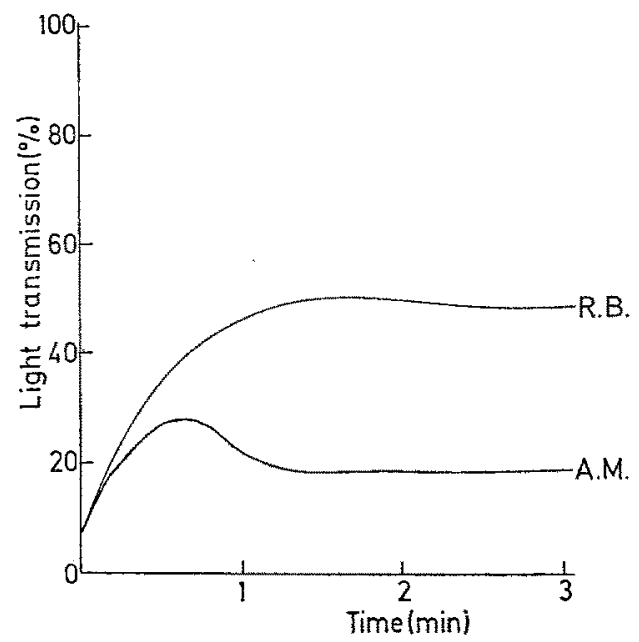

Fig. 3. Recordings of changes in light transmission due to the aggregation of platelets by $1 \mu M$ ADP from a Group $A+$ patient (A.M.) with no retinopathy and a Group B + patient ( . B. .) with deteriorating retinopathy

Table 5. The activities of the ADP-splitting enzyme systems in blood and plasma from selected groups of diabetic and normal subjects

\begin{tabular}{lll}
\hline Subjects (No.) & \multicolumn{2}{l}{$\begin{array}{l}\text { Rate of ADP breakdown } \\
(\mu \mathrm{g} / \mathrm{min})^{\mathrm{a}}\end{array}$} \\
\cline { 2 - 3 } & blood & plasma \\
\hline Normals (26) & $2.6 \pm 0.18$ & $0.95 \pm 0.07$ \\
$\begin{array}{l}\text { Group } A \quad(19) \\
\text { Minimal }\end{array}$ & $2.5 \pm 0.26$ & $0.93 \pm 0.09$ \\
$\begin{array}{l}\text { Retinopathy } \\
\text { Group } B \quad(20)\end{array}$ & $3.0 \pm 0.25$ & $1.11 \pm 0.07$ \\
$\begin{array}{l}\text { Severe } \\
\text { Retinopathy } \\
\text { Group } A+\quad(4)\end{array}$ & $3.4 \pm 0.29$ & $1.27 \pm 0.08$ \\
No \\
$\begin{array}{l}\text { Retinopathy } \\
\text { Group } B+\quad(6) \\
\text { Deteriorating } \\
\text { Retinopathy }\end{array}$ & $2.8 \pm 0.54$ & $0.98 \pm 0.17$ \\
\hline
\end{tabular}

a Results are expressed as Mean I S.IE.M.

The activity of the ADP-splitting enzymes in whole blood and plasma.

The activities of the ADP-splitting enzyme systems in blood and plasma are given in Table 5. The rate of breakdown of $\mathrm{ADP}$ is approximately three times greater in whole blood than in plasma. The rates for the control, Group A and Group B diabetic subjects were found to be: $2.6,2.5$ and $3.0 \mu \mathrm{g} \mathrm{ADP} / \mathrm{ml}$ blood/ 
min and $0.95,0.93$ and $1.11 \mu \mathrm{g} \mathrm{ADP} / \mathrm{ml}$ plasma/min, respectively. In the case of the two smaller groups of diabetic subjects, the values were 3.4 and $2.8 \mu \mathrm{g}$ $\mathrm{ADP} / \mathrm{ml}$ blood/min and 1.27 and $0.98 \mu \mathrm{g}$ ADP $/ \mathrm{ml}$ plasma/min for those in Groups $\mathrm{A}+$ and $\mathrm{B}+$ respeotively. The higher value found in the blood of those long-duration diabetic patients without retinopathy, would result in the more rapid breakdown of ADP and might possibly affect the results of the ADP-activated aggregation experiments. The amount of ADP necessary to initiate platelet aggregation in $1 \mathrm{ml}$ plasma is of the order of $0.5 \mu \mathrm{g}$, which would be removed by the plasma enzyme systems in approximately $30 \mathrm{sec}$. However, the aggregation reaction and incubation at $37^{\circ}$ were allowed to continue for $3 \mathrm{~min}$. This is possible because further $\mathrm{ADP}$ is released into the plasma from the platelets as aggregation takes place. Thus there is a balance between the release and breakdown of ADP, but from the above results, the observed differences in the extent of aggregation in vitro of the platelets from the patients with deteriorating retinopathy, are probably not due to any difference in the activity of the plasma enzyme systems.

Platelet adhesiveness: Although the experimental conditions for the determination of platelet adhesiveness were rigorously standardized, considerable variations were observed even in the control subjects. The values for the 28 controls ranged from $9-79 \%$ with a mean value of $42.6 \pm 3.3 \%$. All the values for the diabetic subjects fell within this wide range. The mean value for the 22 diabetic patients without retinopathy was $36.1 \pm 3.5 \%$ with a range of $12-66 \%$ and for the 22 patients with retinopathy, $41.9 \pm 3.0 \%$ with a range of $22-72 \%$. With these wide ranges of values and relatively small numbers in each group, there were no statistically significant differences between any of the means.

\section{Discussion}

Several investigators have reported that an increase in platelet adhesiveness occurs in diabetes. On the other hand, other observers either have been unable to demonstrate such an increase or have been able to do so only in selected groups of diabetics. Nevertheless, it is often stated that diabetics exhibit increased platelet adhesiveness, and though evidence is accumulating that platelet behaviour in diabetes can be abnormal, the statement that an increase in platelet adhesiveness occurs should be qualified, since it is not generally applicable. In this investigation, the differences in platelet adhesiveness between the 28 control subjects and either the 22 patients with retinopathy or the same number without retinopathy, were not significant. An adaptation of the glass ballotini method of Hellem [7] was used under rigorously controlled conditions, and our results are in agreement with those of Odegaard et al. [12], who used a similar technique. These investigators found that platelet adhesiveness was lower in 25 diabetics when compared with the values obtained from 104 control subjects. Owren [13] quoting unpublished results of Odegaard, using the glass ballotini method of Hellem [7], states that platelet adhesiveness was increased in a group of 50 diabetics, but details of the duration, age and other complications are not given. There is a very wide distribution of normal values for platelet adhesiveness, and to obtain statistically significant results, it is possible that larger groups than those used in this investigation should have been studied. Using either the same glass ballotini method, or the rotating glass bulb method of Payling Wright [16], Mayne et al. [10] have shown that platelet adhesiveness is increased in the case of 140 diabetics when compared with a similar number of control subjects. These investigators pointed out how. ever, that this increase could only be considered on a group basis and that diabetics could not be distinguished by individual results. Increases in platelet adhesiveness have also been reported in diabetics by Breddin [5], who studied 200 patients by a different technique from that used by Mayne et al. [10]. Patient selection has to be taken into consideration and this is well exemplified by the results of Valdorf-Hansen [15], who found no differences in platelet adhesiveness when comparing the mean values for 57 normal subjects with those of 36 diabetics with no clinically recognisable complications, by the method in vivo of Borchgrevenink [1]. Valdorf-Hansen [15] also found that there was no difference in the value for the 18 diabetics with simple retinopathy, but that the platelet adhesiveness was increased in those diabetics who had either proliferative retinopathy, nephropathy or ketoacidosis. Other factors that can influence the results of platelet adhesiveness determinations are the composition of the plasma and the nutritional state of the patient at the time of blood withdrawal. Bridges $e t$ al. [6] using the Payling Wright technique [16], found an increase in platelet adhesiveness in diabetics, which was influenced to a certain extent by the blood glucose level and by the addition of glucose in vitro. No relation however, was found by Shaw et al. [14] between the level of the blood sugar and the extent of platelet adhesiveness, but these workers, using a technique in which the whole EDTA-treated blood was in contact with glass ballotini for $35 \mathrm{~min}$, found a significant increase in platelet adhesiveness in 34 diabetic subjects.

Although Odegaard et al. [12] found no differences in platelet adhesiveness in citrated whole blood between diabetic and normal subjects, these workers demonstrated a significant increase in platelet ad. hesiveness when ADP was added to platelet-rich plasma, before passage through the glass ballotini column. Shaw et al. [14] also found that platelets from diabetic subjects adhered to glass ballotini more than those from control subjects when ADP was added to the heparinized blood. It can therefore be seen that under the appropriate experimental conditions, abnormalities in platelet behaviour do occur in diabetes. 
It was to investigate this phenomenon more fully that studies on ADP-activated aggregation were carried out.

The patients in this study were selected from more than 1800 attending the Out-Patient Clinics at University College and the Whittington Hospitals. It was decided to study a group of patients who had had diabetes for at least 17 years and yet still had no ophthalmoscopically detectable retinopathy, because it was felt that one needed to know why these patients remained so normal in this respect. It was possible to find only 22 patients who qualified for this group when the criteria were lowered, so that no more than a total of five microaneurysms could be found on repeated and careful examination of both fundi. Out of all the patients, only six were found who had no detectable retinopathy at all. In order to accentuate any differences that might be related to the development of retinopathy, the second group consisted of 22 patients with very serious retinopathy, in six of whom the condition actively deteriorated during the course of the experiment. Thus, they are not a representative cross-section of the whole diabetic population, but rather two very special groups in which it was thought that differences in platelet behaviour would be more apparent if these should occur in diabetics as a whole. A group of 28 non-diabetic, age matched, healthy subjects were also studied as controls. From the results, it is apparent that the platelets from either those with serious retinopathy or those with minimal retinopathy do not, when consid. ered on a group basis, aggregate in the presence of ADP either more rapidly or to a greater extent than do the platelets from the control subjects. If one considers however the Group B+ patients, that is those with actively deteriorating retinopathy, then the results show that the platelets from these patients are much more sensitive to the action of ADP. The extent to which these platelets aggregate in the presence of $1 \mu \mathrm{M}$ ADP is the same as that attained by the platelets from the A+ group, that is those without retinopathy, when twice this concentration of the nucleotide is used to initiate the aggregation. The platelets from those with deteriorating retinopathy are similarly more sensitive to the action of 2 and $3 \mu \mathrm{M} A D P$ in respect of the extent of aggregation attained, but there are no significant differences in the rate at which this takes place. The most striking difference however, in the behaviour of platelets from the deteriorating retinopaths, is seen in the stability of the platelet aggregates formed under the influence of low concentrations of ADP. The value of $\mathrm{Gd}$ for the rate of disaggregation was zero at 3 and $2 \mu \mathrm{Y}$ and only 0.03 per cent per second at $1 \mu \mathrm{M}$ ADP, whereas the aggregates from the A+ group all disaggregated at these concentrations of ADP. This failure of platelet aggregates to disaggregate again, however, although very marked in the case of the actively deteriorating retinopaths, is not limited to this group. The aggregates formed in the presence of $1 \mu \mathrm{M}$ ADP, from five of the control subjects and two of the Group A diabetics, also had Gd values of zero.

It would appear therefore, that platelets in vitro can, under the influence of low concentrations of ADP, be shown to clump together to form small stable aggregates, and that this phenomenon is more pronounced in diabetic subjects with deteriorating retinopathy. If this should take place in vivo then occlusion of parts of the microcirculation might occur.

Acknowledgements: The authors wish to thank Dr. L.C.A. Watson, Dr. J. Stewart and Miss S. Stanbridge for their willing help in this research which was generously supported by the M.R.C. and the Prevention of Blindness Committee of the Royal National Institute for the Blind.

\section{References}

1. Borchgrevink, F.: A method for measuring platelet adhesiveness in vivo. Acta med. seand. 168, 157-164 (1960).

2. Born, G.V.R.: Aggregation of blood platelets by Adenosine Diphosphate and its reversal. Nature 194 $927-929$ (1962).

3. - Hume, M.: Effects of the numbers and sizes of platelet aggregates on the optical density of plasma. Nature 215, 1027-1029 (1967).

4. Brecher, G., Cronkite, E.P.: Morphology and enumeration of human blood platelets. J. appl. Physiol. 3, $365-377$ (1950).

5. Breddin, von K.: Úber die gesteigerte Thrombocytenagglutination bei Gefäßkrankheiten. Schweiz. med. Wsohr. 95, 655-660 (1965).

6. Bridges, J.M., Dalby, A.M., Millar, J.H.D., Weaver, J.A.: An effect of D-glucose on platelet stickiness. Lancet $1965 \mathrm{I}, 75-77$.

7. Hellem, A.J.: The adhesiveness of human blood platelets in vitro. Scand. J. elin. Lab. Invest. 12, Suppl. 51, 1-117 (1960).

8. Hunter, P.R., Bloom, A., Kelsey, J.H., Porter, R. Cutaneous capillary resistance and retinal haemorrhage in diabetes. Diabetologia (in press).

9. Kohner, E.M., Dollery, C.T., Paterson, J.W., Oakley, N.W.: Arterial fluorescein studies in diabetic retinopathy. Diabetes 16, $1-10$ (1967).

10. Mayne, E.E., Bridges, J.M., Weaver, J.A.: Platelet adhesiveness, plasma fibrinogen and Factor VIIr levels in diabetes mellitus. Diabetologia $6,436-440$ (1970).

11. Oakley, N., Hill, D.W., Joplin, G.F., Kohner, E.M., Russell Fraser, T.: Diabetic retinopathy. 1. The assessment of severity and progress by comparison with a set of standard fundus photographs. Diabetologia 3, 402-405 (1967).

12. Odegaard, A.E., Skalhegg, B.A., Hellem, A.J.: Increased activity of "Anti-Willebrand Factor" in diabetic plasma. Thromb. Diath. Haem. 11, 27-37 (1964).

13. Owren, P.A.: Coronary Thrombosis, its mechanism and possible prevention by Linolenic Acid. Ann. intern. Med. 63, 167-184 (1965).

14. Shaw, S., Pegrum, G.D., Wolff Sylvia, Ashton, W.L.: Platelet adhesiveness in diabetes mellitus. J. clin. Path. 20, 845-847 (1967).

15. Valdorf-Hansen, F.: Thrombocytes and coagulability in diabetics. Dan. med. Bull. 14, No.9, 244-248 (1967).

16. Wright, Helen P.: The adhesiveness of blood platelets in normal subjects with varying concentrations of anti-coagulants. J. Path. Bact. 53, 255-262 (1941).

Dr. H. Heath

Department of Biochemical Pathology

University College Hospital Medical School

University Street, London,W.C. 1. - England 